\title{
Green approach in anti-corrosion coating by using Andrographis paniculata leaves extract as additives of stainless steel $316 \mathrm{~L}$ in seawater
}

\author{
M.F.F. Maria, ${ }^{1,2}$ W.M.K.W.M. Ikhmal, ${ }^{1,2}$ M.N.N.S. Amirah, ${ }^{3}$ S.M. Manja, ${ }^{3}$ \\ S.M. Syaizwadi, ${ }^{1,2}$ K.S. Chan, ${ }^{1}$ M.G.M. Sabri ${ }^{1,2,4} *$ and A. Adnan ${ }^{1}$ \\ ${ }^{1}$ Advanced Nano Materials (ANoMa) Research Group, School of Fundamental Science, \\ Universiti Malaysia Terengganu, 21030 Kuala Nerus, Terengganu, Malaysia \\ ${ }^{2}$ Materials and Corrosion Research Group, Universiti Malaysia Terengganu, \\ 21030 Kuala Nerus, Terengganu, Malaysia \\ ${ }^{3}$ School of Ocean Engineering, Universiti Malaysia Terengganu, \\ 21030 Kuala Nerus, Terengganu, Malaysia \\ ${ }^{4}$ Institute of Tropical Biodiversity and Sustainable Development, Universiti Malaysia \\ Terengganu, 21030 Kuala Nerus, Terengganu, Malaysia \\ *E-mail: mohdsabri@umt.edu.my
}

\begin{abstract}
The analysis of anticorrosion coating by using Andrographis paniculata (kalmegh) leaves extract (KLE) as an additive to protect stainless steel 316L that immersed in seawater environment was successfully carried out. The anti-corrosive coating is the combination of selected binder, pigment, solvent, and additive. Andrographis paniculata leaves extract was selected as an additive due to excellent antioxidant properties. There are five types of coating with different concentration which are $\mathrm{C} 1$ (0 wt.\%), C2 (3 wt.\%), C3 (6 wt.\%), C4 (9 wt.\%) and C5 (12 wt.\%). The coated substrate the immersed in seawater for 30 days and taken out for each subsequent 10 days for analysis. The analysis involves optical, electrochemical, and morphology studies. A few techniques involve including of Fourier transform infrared spectroscopy (FTIR), ultraviolet-visible spectroscopy (UV-Vis), electrochemical impedance spectroscopy (EIS), potentiodynamic polarization (PP) and scanning electron microscope with energy-dispersive X-ray spectroscopy (SEM/EDS). The result of FTIR shows several functional group presence in the KLE that can enhance anti-oxidation properties such as phenol, carboxylic acid, carbonyl, and amide. The presence of andrographolide compound obtained from UV-vis analysis at peak absorption spectrum $229 \mathrm{~nm}$. Electrochemical analysis result from EIS, the most efficiency coating was predicted at C3. Hence, it has higher $R_{\mathrm{ct}}$ value and low $C_{\mathrm{dl}}$ value. The result in EIS is corresponding to PP; hence the result of corrosion rate at $\mathrm{C} 3$ is the lowest value, which is $0.00211 \mathrm{~mm} /$ year at $30^{\text {th }}$ day immersion. The observation on the surface morphology of the coating also shows that $\mathrm{C} 3$ that has a smooth surface with less pitting, cracks, and salt precipitate when compared to another coating. The addition of KLE increases the efficiency of anticorrosion coating with optimum concentration, which is 6 wt.\%.
\end{abstract}


Key words: corrosion, coating, stainless steel, seawater, Andrographis paniculata.

Received: July 29, 2019. Published: August 19, 2019

doi: $\underline{10.17675 / 2305-6894-2019-8-3-13}$

\section{Introduction}

Corrosion is the external disintegration of metals or alloys in particular condition. Several metals evidence a great corrosion resistance than others and this can be ascribed to a few particular points such as their chemical elements, the environment of electrochemical reactions itself and others $[1,2]$. The problem that causes by corrosion not only intrude the economic, but it might also disturb the social environment and the safety and health of the people, that live nearby corrosion environment or working in the industries. One of the most industries that influenced by corrosion problem is the oil industry such as in Mexico due to this phenomenon bring to bear its consequence from every second of oil extraction on, creates a continuous fight opposed to it [3]. Corrosion cannot be stopped but can be slow down. The structure that undergoes marine corrosion tends to experience crevice corrosion, pitting corrosion, and microbial corrosion [4]. Corrosion can cause failure to metallic structure in the industry thus increase the monetary problem, for example, marine industry in the United States has reported that $\$ 785$ million out of $\$ 810$ million used for the maintenance and repairs and $\$ 1.12$ billion spend for new construction [5].

Austenitic AISI or stainless steel 316L (SS316L) is stainless steel that commonly used in marine industries due to its properties that have substantial resistant towards the marine environment. Regularly, a failure that happens in SS316L in the marine environment is hazardous, which is localized corrosion [6]. SS316L chemical constituent consists of carbon, manganese, silicon, chromium, nickel, molybdenum, phosphorus, sulphur, nitrogen, and iron [7]. As for this research, the coating is a suitable method. Several ways have believed can prevent corrosion and also can increase the lifetime of the metallic and alloy structure [8]. There are five basic things in corrosion control practice, which are design, inhibitor, cathodic protection, material selection, and coating [9-11]. As for this research, the coating is a suitable method. Coating historically can give excellent protection to the metals against corrosion from the aggressive environment [12]. There are two types of coating which are an organic and inorganic coating. An organic coating is believed to give great protection towards the coated metal, especially when the coated metal exposed in the marine environment that rich with chloride ions [13].

The coating system consists of four main components, which are binders, pigments, additives, and solvent. Each component has its specialty and function in the coating. In the coating system, binder refers to substances that hold the particles of pigment together in paint and a major component presence in the paint. Pigment plays the main role in contributing colours and also act as filler in the coating or paint $[14,15]$. Solvent plays a role as a carrier that allows the paint to be coated on the surface of the steel. Solvents are used to control the viscosity of the coatings for an acceptable application. Solvents give effect to the flow and levelling, drying time, gloss, etc. [16]. The additive is a special 
substance that gives a huge impact on paints with a small quantity added in the paints. The uses of additive with the right time, order, and proportion will help the improvement in the coating system. The improvement that additive can helps maybe in the form of appearance paint durability or flow of the paints. In this research, WW Gum Rosin acts as a binder due to its strong adhesion and anticorrosive properties [17]. There are two pigments consist of the coating, which is, zinc oxide $(\mathrm{ZnO})$ and calcium carbonate $\left(\mathrm{CaCO}_{3}\right)$. Form previous research, $\mathrm{CaCO}_{3}$ and $\mathrm{ZnO}$ improved the coating properties such as corrosion resistance, UV resistance, and mechanical strength such as scratch and scraped area [18]. Besides, $\mathrm{CaCO}_{3}$ also has been chosen as a pigment in the coating due to its low cost and easily get [19]. Methyl-isobutyl ketone (MIBK) was chosen as a solvent in the coating component due to the price, solubility, and evaporation rates. MIBK also environmentally friendly compared to another usual solvent such as xylene and toluene, which affect the consumers when they start to evaporate [20].

Corrosion additive plays a very important role in protecting engineering materials, and in recent years, many new corrosion additives are developed [21]. The toxicity of the environment caused by synthetic additive become an attraction to the researcher nowadays. To overcome this problem, the usage of a natural additive such as plant have been concerned. The usage of plant as an additive can reduce the toxicity of the environment that cause by the synthetic additive. This is because plant extract is environmentally friendly, biodegradable, and do not contain heavy metal. Other than that, the plant is inexpensive, readily available, and renewable [22, 23]. Andrographis paniculata (Burm. F) Nees, commonly known as the "king of bitters", is an herbaceous plant belonging to Acanthaceae and mostly discovered for tropical and subtropical Asia, Southeast Asia, and also India [24, 25]. In India, Andrographis paniculata has been known as "Kalmegh"; over China it may be known as "Chuan-Xin-Lian"; to Thailand it may be known as "Fah Tha Lai"; Previously, Malaysia it may be known as "Hempedu Bumi"; to Japan it is known as "Senshinren"; and in Scandinavian nations it is known as "green chiretta" [26, 27]. Andrographolide is the main constituent, and it also the active principle of the plant [28]. The previous study showed that the anti-oxidant effect elucidated by aqueous Andrographis paniculata is due to its ability to activate the anti-oxidant enzyme that catalyzes the reactions of oxidants [29]. Thus the evaluation of plant extract as additives is believed to become an excellent anticorrosion coating to overcome corrosion problem.

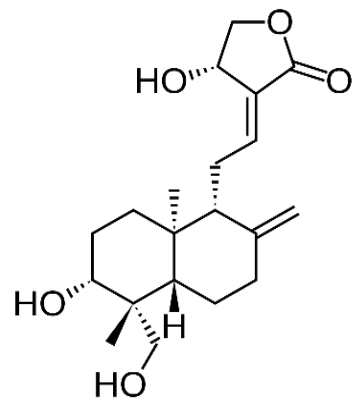

Figure 1. Andrograpolide compound [30]. 


\section{Experimental}

\subsection{Sample preparation}

Stainless steel $316 \mathrm{~L}$ was cut into $25 \times 25 \times 2 \mathrm{~mm}$. Then, the substrate mechanically polished using 800, 1000, and 1200 emery paper is lubricated with distilled water to removes the oxide layer. After that, the substrate was clean by using acetone and wash again using distilled water before dry it at room temperature. The substrate was then stored in a dry box until used.

\subsection{Extract preparation}

Kalmegh leaves powder was weighed and soaked with $80 \%$ of ethanol with ratio 1:10. The mixture then shook using a shaker with $200 \mathrm{rpm}$ speed for 24 hours. The mixture then filtered using vacuum pump before evaporated using a rotary evaporator at $40^{\circ} \mathrm{C}$ water bath and cooling compressor $10^{\circ} \mathrm{C}$ to get the crude extract [31]. Crude extract obtained the stored in the chiller until used.

\subsection{Coating formulation}

The coating was a mixture with binder, pigment, solvent, and additive. The coating was prepared by combining binder (WW Rosin) and pigments $\left(\mathrm{ZnO}\right.$ and $\mathrm{CaCO}_{3}$ ) first then followed by solvent (MIBK) and an additive which is kalmegh leaves extract (KLE) [32]. Five types of the coating were produced by using different weight percentage of KLE, which are C1 (0 wt.\%), C2 (3 wt.\%), C3 (6 wt.\%), C4 (9 wt.\%) and C5 (12 wt.\%).

\subsection{Optical studies}

Optical studies of extract and coating involve two characterizations which are Fourier Transform Infrared and Ultraviolet-visible Spectroscopy (UV-Vis) The FTIR spectrometer was used to identify the functional groups of Kalmegh leaves extract by observing at the vibrational motion of bonds in the molecule. The absorbance of the extract solution was measured by using Lambda 256 Perkin Elmer UV/VIS spectrometer. UV-Vis Spectroscopy is an instrument that usually used to analyze the absorption of the polymer and dyes. The data obtained from FTIR and UV-Vis, measurement then plotted using Origin Pro 8.

\subsection{Immersion test}

The tests are carried out for 30 days on the open site. Samples will be left hanging on a frame underwater and taken out for each subsequent 10 days for analysis. The substrates were immersed at Merang, Setiu. The immersion site is located at $5^{\circ} 32^{\prime} 17.7^{\prime \prime} \mathrm{N}$, $102^{\circ} 56^{\prime} 44.9$ ' E. 


\subsection{Electrochemical studies}

Electrochemical studies involve Electrochemical Impedance (EIS) and Potentiodynamic Polarization (PP). EIS was used to study the impedance characteristic as well as capacitance behavior of the substrate in the presence and absence of KLE. Impedance measurement was carried out using AUTO LAB PGSTAT302N controlled by software NOVA 10.1 with parameter frequency range $100 \mathrm{kHz}$ to $10 \mathrm{kHz}$. Potentiodynamic polarization (PP) is the most common polarization method used for measuring corrosion resistant. The characterization was to study the anodic and cathodic polarization of the coated and uncoated samples that involves several parameters such as $i_{\text {corr }}, E_{\text {corr, }}$ and corrosion rate.

\subsection{Morphology studies}

The morphology of coated and uncoated substrates was observed using JSM-6390LA Scanning Electron Microscope (SEM) to investigate the interaction of the surface of coated steels with seawater. The samples were dried before coated with fine gold spray using fine coater machine. The surface condition was examined with x100 magnification and $15 \mathrm{kV}$ of accelerated voltage. The elemental characterization also conducted using Energy Dispersive X-Ray (EDX) that performed along with SEM.

\section{Results and discussion}

\subsection{Optical studies}

Figure 2 shows the peak on the graph that show the functional group that detected in kalmegh leaves extract by using FTIR Spectroscopy. The functional groups that were observed include alcohol, carboxylic acid, alkynes, nitriles, amide, nitro, and carbonyl. At wavenumber $3352.28 \mathrm{~cm}^{-1}$, a strong and broad peak observed which represent the alcohol or phenolic group $(\mathrm{O}-\mathrm{H})$ stretching vibration was detected. Strong appearance of carboxylic acid $(\mathrm{O}-\mathrm{H})$ was observed at wavelength $2918.3 \mathrm{~cm}^{-1}$. The weak and spectrum were obtained at wavelength $2324.22 \mathrm{~cm}^{-1}$ and $2227.78 \mathrm{~cm}^{-1}$, which represent alkynes $(\mathrm{C}=\mathrm{C})$ and nitriles $(\mathrm{C} \equiv \mathrm{N})$. Amide $(\mathrm{C}=\mathrm{O})$ group was represented at the wavenumber $1678.07 \mathrm{~cm}^{-1}$. According to the peak value of $1406.11 \mathrm{~cm}^{-1}$, the peak present nitro asymmetric stretch $\left(\mathrm{NO}_{2}\right)$ with strong appearance while at wavelength $1033.85 \mathrm{~cm}^{-1}$ was determined to be a strong vibration of the carbonyl group $(\mathrm{C}=\mathrm{O})$ [1].

A functional group such as phenol, carboxylic acids, carbonyl, and amide is expected to provide antioxidant properties because they contain heteroatoms. That functional group is believed to donate the lone pair electron to the empty orbital and help the metal to achieve a stable state. This also will increase the adhesive property of the coating matrix [33]. 


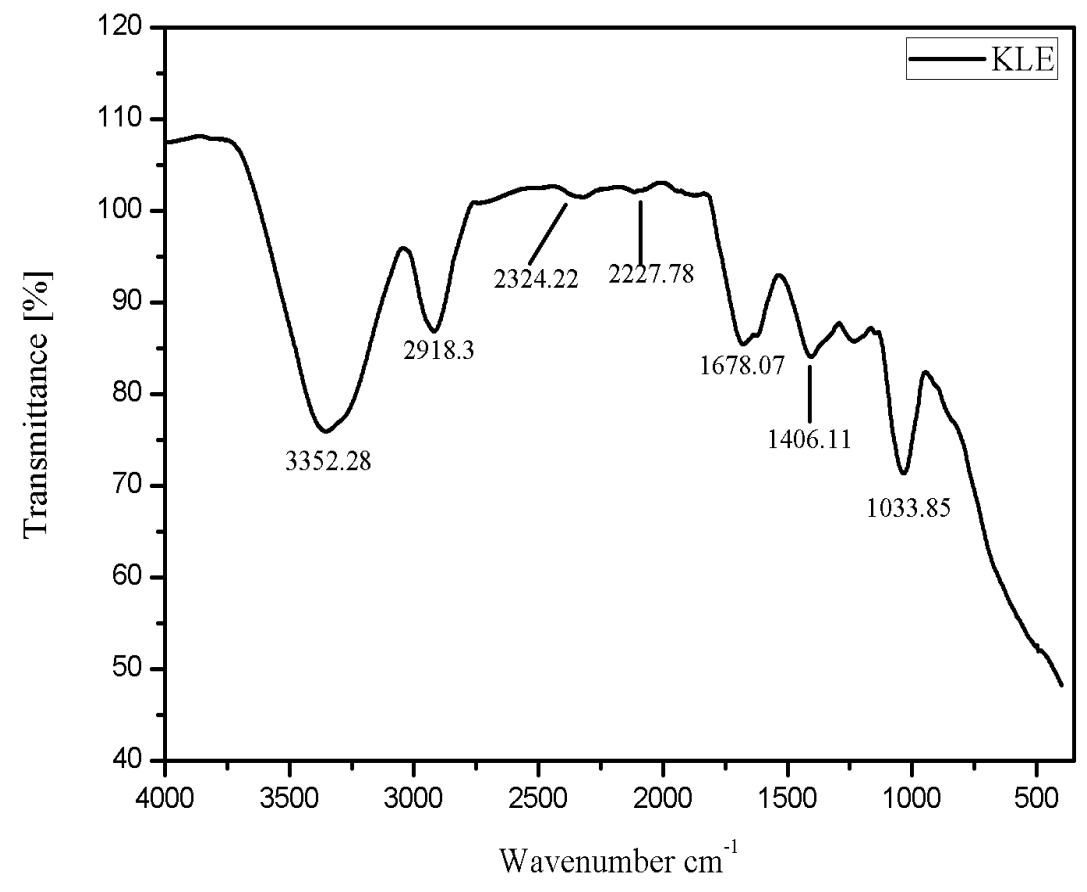

Figure 2. FTIR spectrum for kalmegh leaves extract.

$\mathrm{UV}$-Vis spectrometer was used to measure the amount of light absorbance by the compounds of kalmegh leaves extract at a certain wavelength. The range of the wavelength used was between 200 to $800 \mathrm{~nm}$. Since most plant compound usually falls in this region. Figure 3 shows the UV-Vis absorption spectrum detected in KLE. Based on the graph shown below, it was found that absorption observed at $229 \mathrm{~nm}$ show the presence of andrographolide compound [34].

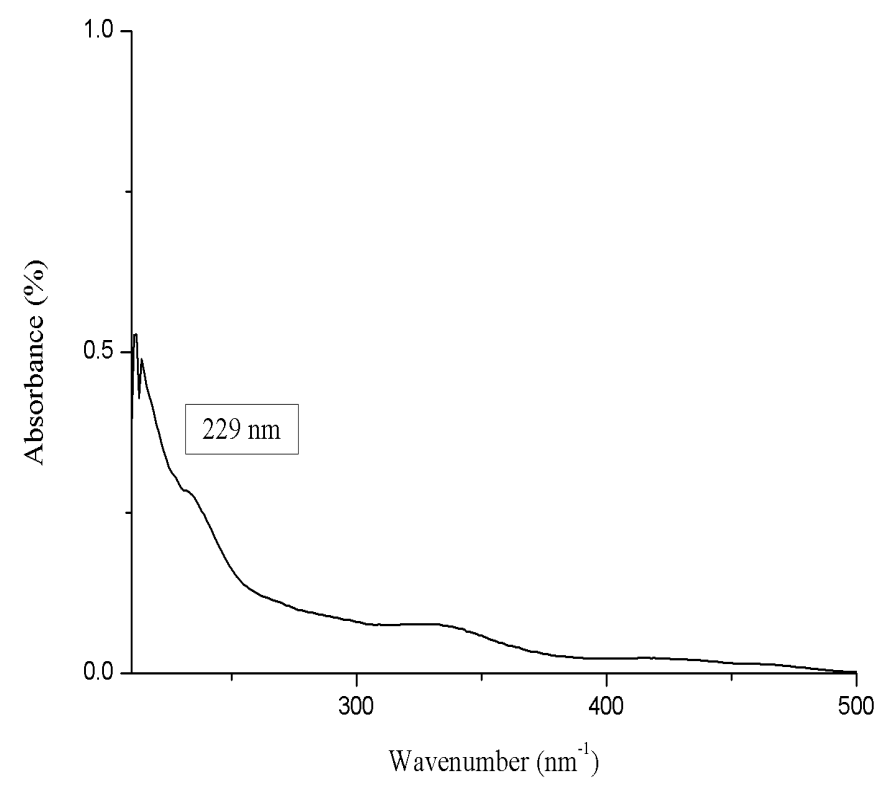

Figure 3. UV-Vis spectrum of kalmegh leaves extract. 


\subsection{Electrochemical Impedance Spectroscopy (EIS)}

EIS is a common technique to measure and analyze the behavior of coating or metal after being exposed to a harsh medium. The method used equivalent circuits to represent the phenomenon of corrosion where parameters involve are charge transfer resistance $\left(R_{\mathrm{ct}}\right)$ and double-layer capacitance $\left(C_{\mathrm{dl}}\right) . R_{\mathrm{ct}}$ is to measure the susceptibility of metal to corrosion while $C_{\mathrm{dl}}$ measure amount of water absorb by coating. The Nyquist plot shows the impedance behaviour of uncoated and coated stainless steel $316 \mathrm{~L}$ that immersed in seawater for 10 days, 20 days and 30 days.

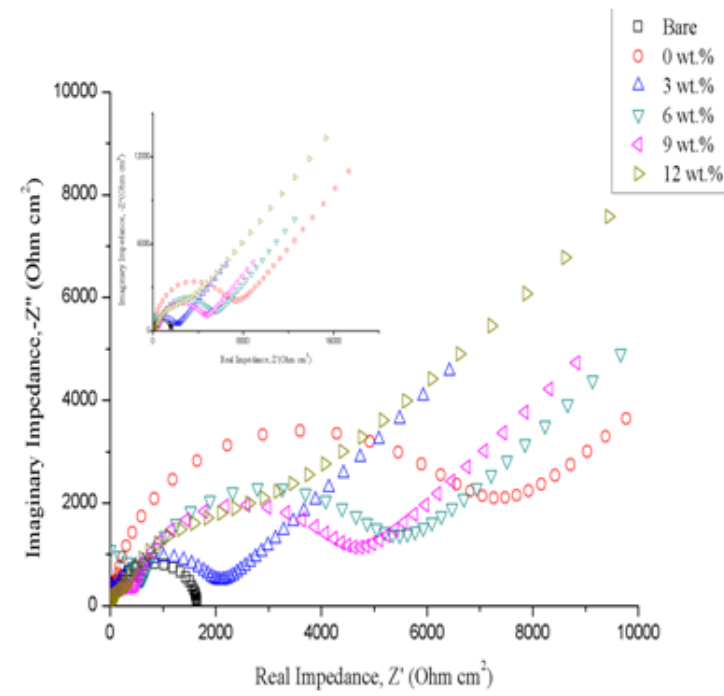

(a)

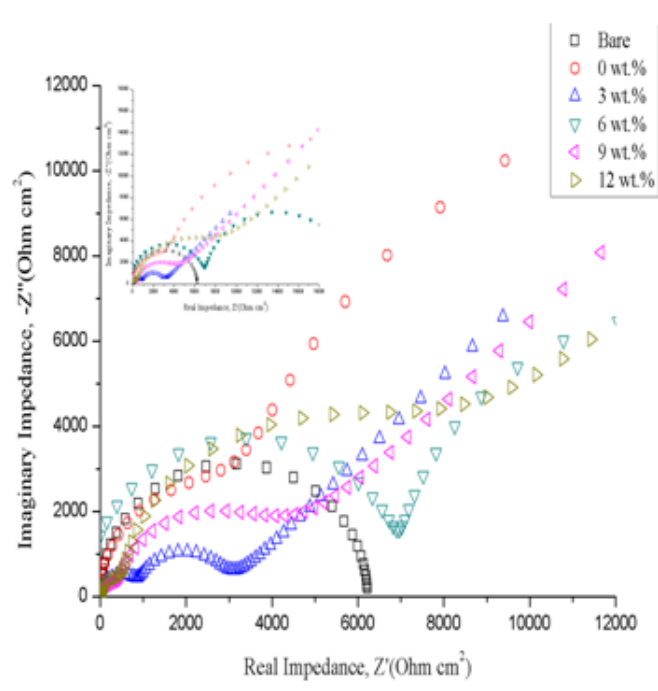

(b)

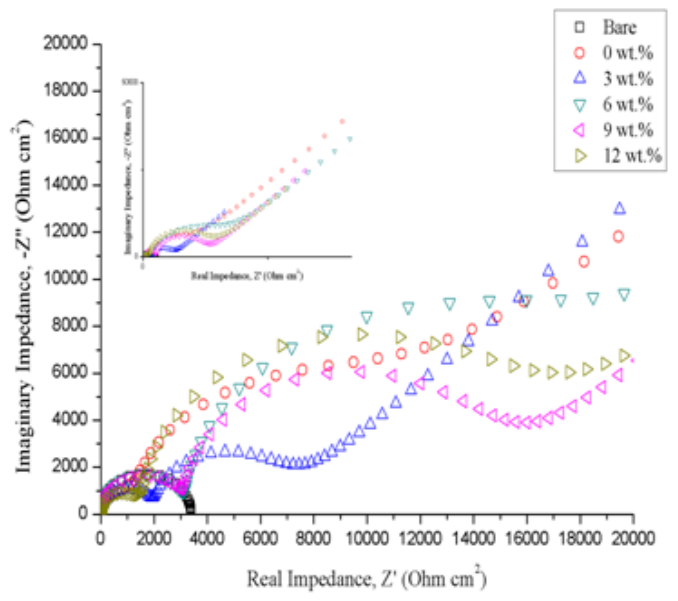

(c)

Figure 4. Nyquist plot for a) 10 days, b) 20 days, and c) 30 days immersion. 
Figure 4 represents the Nyquist plots for (a) 10 days (b) 20 days and (c) 30 days. The value of $R_{\mathrm{ct}}$ and $C_{\mathrm{dl}}$ of all immersion period was recorded in Table 1 . From the tabulated data of $R_{\mathrm{ct}}$ value, the highest $R_{\mathrm{ct}}$ value for 10 days immersion was at the coating that has 6 wt.\% of KLE. Same goes to the samples that immersed for 20 days and 30 days. The highest value of $R_{\mathrm{ct}}$ also at C3, which is a coating that added with 6 wt.\% of KLE. Hence, the optimum value of KLE based on the resistance data obtained signifies that $6 \mathrm{wt} \%$ of KLE is the best concentration for the coating system.

As for the double-layer capacitance $\left(C_{\mathrm{dl}}\right)$, the value during the period of immersion seems not consistent. The increase $C_{\mathrm{dl}}$ value generalized the increasing value of water uptake by the coating as the time increase. Based on Table 1, the lowest value of $C_{\mathrm{dl}}$ for 10 days immersion is at $\mathrm{C} 5$, which is $1.18 \mu \mathrm{F}$. As for 20 days and 30 days immersion, the lowest value of $C_{\mathrm{dl}}$ obtained both is at C3, which is coating with 6 wt.\% KLE. Contrarily, based on Table 1 , the values of $C_{\mathrm{dl}}$ for $\mathrm{C} 3$ displayed a typical trend where it exhibited an almost constant reading during the $20^{\text {th }}$ to $30^{\text {th }}$ days.

Table 1. Impedance parameters.

\begin{tabular}{|c|c|c|c|}
\hline Days & Coating & $R_{\mathrm{ct}}\left(\Omega \cdot \mathrm{cm}^{2}\right)$ & $C_{\mathrm{dl}}(\mathbf{F})$ \\
\hline \multirow{6}{*}{10} & Bare & $1.65 \mathrm{k}$ & $37.6 \mu$ \\
\hline & $\mathrm{C} 1(0 \%)$ & $6.32 \mathrm{k}$ & $3.35 \mu$ \\
\hline & $\mathrm{C} 2(3 \%)$ & $1.75 \mathrm{k}$ & $2.38 \mu$ \\
\hline & $\mathrm{C} 3(6 \%)$ & $48.2 \mathrm{k}$ & $4.32 \mu$ \\
\hline & $\mathrm{C} 4(9 \%)$ & $3.15 \mathrm{k}$ & $8.11 \mu$ \\
\hline & C5 (12\%) & $2.02 \mathrm{k}$ & $1.18 \mu$ \\
\hline \multirow{6}{*}{20} & Bare & $6.23 \mathrm{k}$ & $79.2 \mu$ \\
\hline & $\mathrm{C} 1(0 \%)$ & $12.3 \mathrm{k}$ & $578 \mathrm{n}$ \\
\hline & $\mathrm{C} 2(3 \%)$ & $1.82 \mathrm{k}$ & $2.57 \mu$ \\
\hline & C3 (6\%) & $16.3 \mathrm{k}$ & $925 n$ \\
\hline & $\mathrm{C} 4(9 \%)$ & $3.15 \mathrm{k}$ & $4.31 \mu$ \\
\hline & C5 (12\%) & $6.36 \mathrm{k}$ & $5.16 \mu$ \\
\hline \multirow{6}{*}{30} & Bare & $3.40 \mathrm{k}$ & $85.5 \mu$ \\
\hline & $\mathrm{C} 1(0 \%)$ & $8.17 \mathrm{k}$ & $1.55 \mu$ \\
\hline & $\mathrm{C} 2(3 \%)$ & $4.57 \mathrm{k}$ & $4.20 \mu$ \\
\hline & C3 (6\%) & $14.0 \mathrm{k}$ & $512 \mathrm{n}$ \\
\hline & $\mathrm{C} 4(9 \%)$ & $11.0 \mathrm{k}$ & $1.34 \mu$ \\
\hline & C5 (12\%) & $13.4 \mathrm{k}$ & $5.08 \mu$ \\
\hline
\end{tabular}




\subsection{Tafel polarization}

The Tafel plot in Figure 5 shows the polarization of anodic and cathodic behavior of corrosion of sample that immersed in seawater for (a) 10 days, (b) 2 days and (c) 30 days. The parameter involves in this characterization are corrosion potential $\left(E_{\text {corr }}\right)$, corrosion density $\left(i_{\text {corr }}\right)$, and corrosion rate $(C R)$. The data collected for this characterization tabulated in Table 2. By referring the Tafel plots in Figure 5, the anodic and cathodic slope changes with the different addition of KLE in the coating. This is because of retardation process occurs in both section that corresponding to adsorption of inhibitor molecule [35].

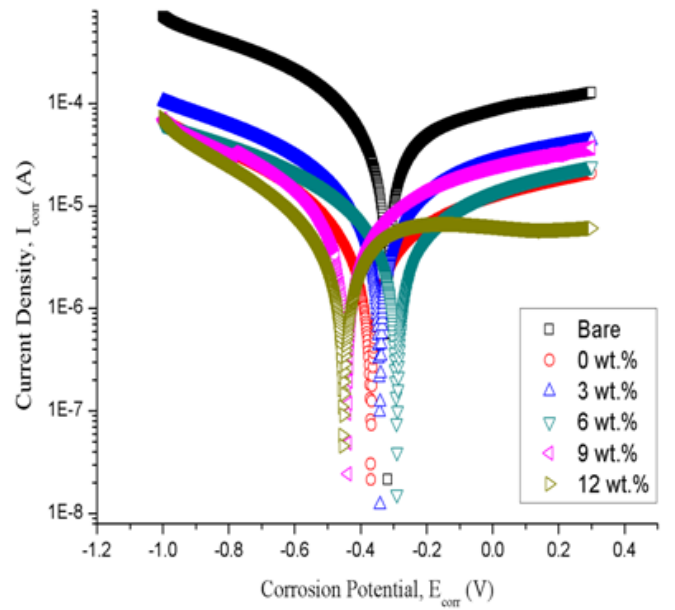

(a)

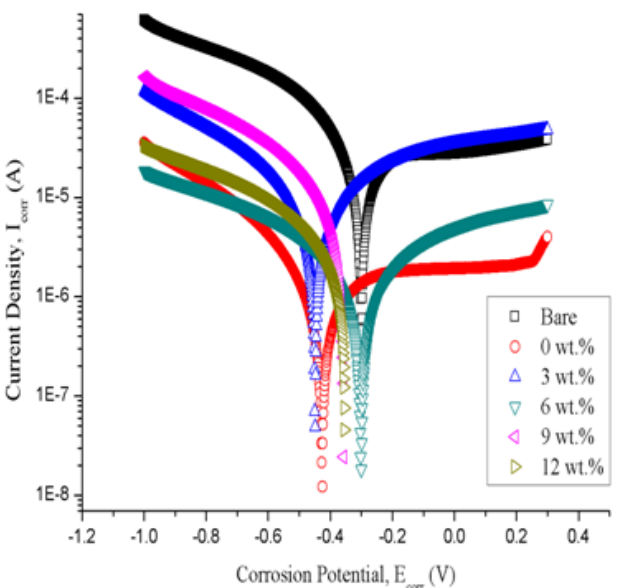

(b)

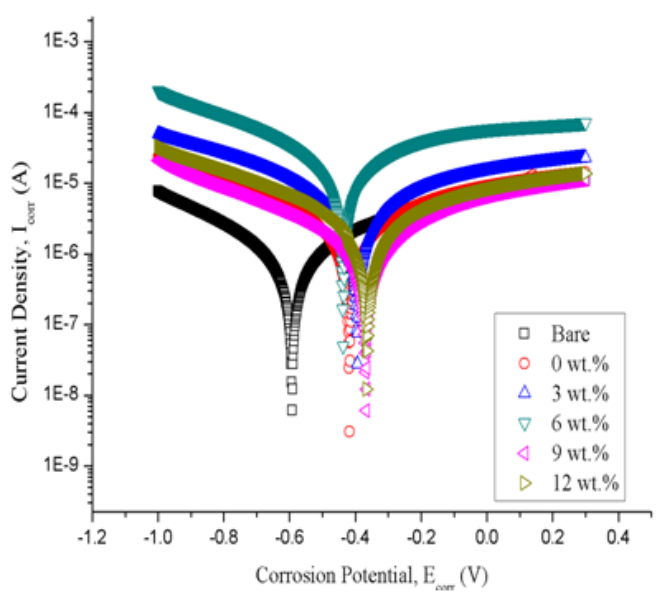

(c)

Figure 5. Tafel plot for a) 10 days, b) 20 days, and c) 30 days immersion.

Corrosion current density $\left(i_{\text {corr }}\right)$ denotes the corrosion progress and acts as the indicator for the type of inhibitive action. As the $i_{\text {corr }}$ increase, corrosion progress is faster. From Table 2, the lowest $i_{\text {corr }}$ value for 10 days immersion is at $\mathrm{C} 3$ which is $3.15 \cdot 10^{-5} \mathrm{~A} \cdot \mathrm{cm}^{2}$ that corresponding to the value of corrosion rate $0.052661 \mathrm{~mm} /$ year that also the lowest value compared to others coating. As for samples that immersed for 
20 days and 30 days, the excellent coating behavior also at $\mathrm{C} 3$ due to the lowest value of $i_{\text {corr }}$ and corrosion rate. The value of $i_{\text {corr }}$ and corrosion rate for 20 days immersion is $1.5494 \cdot 10^{-6} \mathrm{~A} \cdot \mathrm{cm}^{2}$ and $0.35689 \mathrm{~mm} /$ year while for 30 days immersion is $1.26 \cdot 10^{-6} \mathrm{~A} \cdot \mathrm{cm}^{2}$ and $0.00211 \mathrm{~mm} /$ year. The lowest $E_{\text {corr }}$ value for all immersion duration was identified at C3 explained the limitation of the absorption of KLE into coating formulation; hence, it can be assigned as the optimum value of KLE needed in the coating. The performance of the coating decrease when it reaches a certain amount of extract concentration [36].

Table 2. Tafel polarization data.

\begin{tabular}{ccccc}
\hline Days & Coating & $\begin{array}{c}\text { Corrosion } \\
\text { potential, } \\
\boldsymbol{E}_{\text {corr }}(\mathbf{V})\end{array}$ & $\begin{array}{c}\text { Corrosion } \\
\text { current density, } \\
\boldsymbol{i}_{\text {corr }}\left(\mathbf{A} \cdot \mathbf{c m}^{2}\right)\end{array}$ & $\begin{array}{c}\text { Corrosion Rate } \\
(\mathbf{m m} / \mathbf{y e a r})\end{array}$ \\
\hline \multirow{3}{*}{10} & Bare & -0.31864 & 0.000472 & 0.7888 \\
& C1 (0\%) & -0.39639 & $5.20 \cdot 10^{-5}$ & 0.086937 \\
& C2 (3\%) & -0.34222 & $5.53 \cdot 10^{-5}$ & 0.092358 \\
& C3 (6\%) & -0.29054 & $3.15 \cdot 10^{-5}$ & 0.052661 \\
& C4 (9\%) & -0.43894 & $5.60 \cdot 10^{-5}$ & 0.093588 \\
& C5 (12\%) & -0.45413 & $6.17 \cdot 10^{-5}$ & 0.10316 \\
\hline \multirow{3}{*}{20} & Bare & -0.29883 & 0.000191 & 0.00103 \\
& C1 (0\%) & -0.42648 & $6.1915 \cdot 10^{-6}$ & 0.56925 \\
& C2 (3\%) & -0.44935 & $3.26 \cdot 10^{-5}$ & 1.017 \\
& C3 (6\%) & -0.30136 & $1.5494 \cdot 10^{-6}$ & 0.35689 \\
& C4 (9\%) & -0.35681 & $7.4371 \cdot 10^{-5}$ & 1.1175 \\
& C5 (12\%) & -0.35269 & $6.8958 \cdot 10^{-6}$ & 0.75241 \\
\hline Bare & -0.41104 & 0.000227 & 0.37863 \\
& C1 (0\%) & -0.37406 & $4.92 \cdot 10^{-6}$ & 0.057119 \\
& C2 (3\%) & -0.39497 & $4.64 \cdot 10^{-5}$ & 0.077517 \\
& C3 (6\%) & -0.32123 & $1.26 \cdot 10^{-6}$ & 0.00211 \\
& C4 (9\%) & -0.36738 & $6.61 \cdot 10^{-6}$ & 0.011047 \\
& C5 (12\%) & -0.36613 & $2.29 \cdot 10^{-5}$ & 0.038247 \\
\hline
\end{tabular}

\subsection{Morphology study}

SEM/EDS is one of the common techniques to observe the surface condition of the material. In this study, the coated and uncoated stainless steel $316 \mathrm{~L}$ that immersed in seawater for 30 days was observed to know the surface condition after exposed to an aggressive environment. Figure 6(a) shows the surface condition of bare stainless steel 
316L. From the image observed, the surface of the bare metal was deposited with salt as we can see the white precipitate that presence on the surface of the specimen. Figure 6(b) is the substrate that coated with the coating without the addition of leaves extract. The surface of the coating was severely damaged with the presence of cracks and pitting. The condition of coating with 3 wt.\%, in Figure 6(c) also undergoes damages on the surface due to the pitting occurs on the surface of the coating and a lot of salt deposited. For coating that contains 6 wt.\% of leaves extract in Figure 6(d), the surface of the coating is smooth with no pitting or holes shows while for Figure 6(e) and (f) the surface of the coating with 9 wt. $\%$ and 12 wt. $\%$ of leaves extract have a rough surface when compared with Figure 6(d).

From the observation, coating with 6 wt.\% shows the surface that smooth and fewer damages compared to other coating. The excellent of the surface condition of coating is due to the presence of an optimum concentration of leaves extract. The presence of leaves extract can enhance the properties of the coating when the extract will create a strong carbon chain and increase the adhesion properties of coating, thus prevent the coating from degrading. The pitting or cracks that occur on the coating surface will lead to degradation of coating because it will enhance the water enters the coating.

The element composition that observed under EDX measurement showed in Table 3. From the Table 3, the composition of the chromium element on the surface of the coating with 6 wt.\% (C3) is the lowest compared to $\mathrm{C} 1, \mathrm{C} 2$, and bare metal. This is because the coating can prevent the oxidation of stainless steel 316L to happen. The oxidation of stainless steel 316L will release chromium ions that harmful toward a few species of aquatics life by affecting the organ of the fish such as gills, kidney, and liver [37].
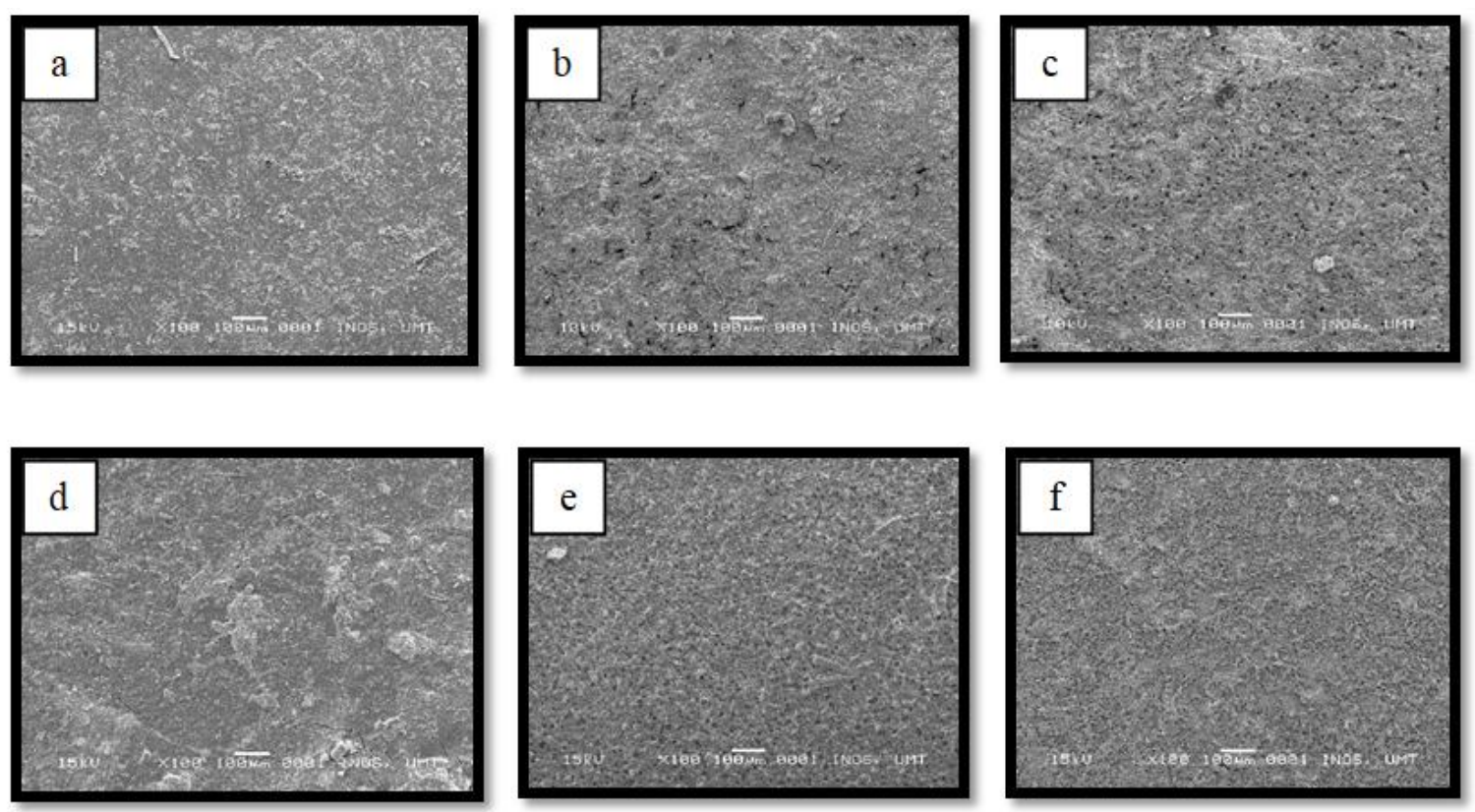

Figure 6. SEM image for sample immersed for 30 days a) bare metal, b) C1, c) C2, d) C3, e) $\mathrm{C} 4$, and f) C5. 
Table 3. Element composition of metals that immersed for 30 days.

\begin{tabular}{ccccc}
\hline \multirow{2}{*}{ Element } & \multicolumn{3}{c}{ Mass (\%) } \\
\cline { 2 - 4 } & Bare & C1 (0 wt. \%) & C2 (3 wt. \%) & C3 (6 wt. \%) \\
\hline $\mathrm{Na}$ & 2.18 & 38.78 & 47.21 & 53.37 \\
$\mathrm{Cl}$ & 0.94 & 33.10 & 43.63 & 27.71 \\
$\mathrm{Cr}$ & 58.79 & 5.28 & 5.02 & 4.99 \\
$\mathrm{Ni}$ & 38.09 & 22.85 & 4.13 & 13.93 \\
Total & 100.00 & 100.00 & 100.00 & 100.00 \\
\hline
\end{tabular}

\section{Conclusion}

From this research conducted, it is concluded that:

1. The coating with the addition of Andrographis paniculata leaves extract proved that is successful and able to slow down the corrosion process in seawater.

2. FTIR analysis shows the functional group such as carbonyl and phenol, inhibit the mechanism of corrosion.

3. The electrochemical studies indicate that the efficiency of coating with leaves extract as an additive increase until certain concentration achieve.

4. From observation under SEM/EDX measurement, the surface condition of coating contains an optimum concentration of leaves extract to improve the capability of the surface condition.

5. The addition of LLE into the coating matrix decreased the corrosion rate when the extract was used up to $6 \mathrm{wt} . \%(\mathrm{C} 2)$ and further increase yields in higher corrosion rate.

\section{Acknowledgements}

The authors gratefully thank the financial support of the Fundamental Research Grant Scheme (Vot no. 59537). The authors also extend an appreciation for the support of analytical analysis and testing center of Universiti Malaysia Terengganu.

\section{References}

1. F. M. F. Maria, K.S. Chan and H.Y. Lee, Corrosion Inhibitive Effect of Thiourea on 1100 Aluminium Alloy Sheet in Hydrochloric Acid Solution, Malaysian J. Anal. Sci., 2018, 22, no. 6, 950-956.

2. A. Popoola, O. Olorunniwo and O. Ige, Corrosion resistance through the application of anti-corrosion coatings, Dev. Corros. Prot., Ed: M. Aliofkhazraei, IntechOpen, 2014, 241-270. doi: $\underline{10.5772 / 57420}$ 
3. R.M. Palou, O. Olivares-Xomelt and N.V. Likhanova, Environmentally Friendly Corrosion Inhibitors, Dev. Corros. Prot., Ed: M. Aliofkhazraei, IntechOpen, 2014, 431-465. doi: 10.5772/57252

4. M. Safiuddin, Occurrences of Corrosion: Causes and Prevention, BRAC U. J., 2006, 3, no. $1,71-74$.

5. K. De Baere, H. Verstraelen, P. Rigo, S. Van Passel, S. Lenaerts and G. Potters, Reducing the Cost of Ballast Tank Corrosion: An Economic Modeling Approach, Mar. Struct., 2013, 32, 136-152. doi: 10.1016/j.marstruc.2012.10.009

6. A.U. Malik and S.A. Al-Fozan, Pitting Behaviour of type 316L SS in Arabian Gulf Seawater, Technical Report No. SWCC (RDC)-22, 1992.

7. S. Refaey, F. Taha and A.A. El-Malak, Inhibition of Stainless Steel Pitting Corrosion in Acidic Medium by 2-Mercaptobenzoxazole, Appl. Surf. Sci., 2004, 236, no. 1-4, 175-185. doi: 10.1016/j.apsusc. 2004.04.016

8. K. Palanisamy, V. Devabharathi and N.M. Sundaram, Corrosion Inhibition Studies of Mild Steel With Carrier Oil Stabilized of Iron Oxide Nanoparticles Incorporated Into A Paint, Int. J. ChemTech Res., 2014, 7, no. 4, 1661-1664.

9. P. Fauchais and A. Vardelle, Thermal Sprayed Coatings Used Against Corrosion and Corrosive Wear, Advanced Plasma spray Applications, 2012, Ed.: J. Hamidreza, Rijeka, Croatia, IntechOpen. doi: 10.5772/34448

10. H. Hajar, F. Zulkifli, M. Mohd Sabri and W. Wan Nik, Protection Against Corrosion of Aluminum Alloy in Marine Environment by Lawsonia inermis, Int. J. Corros., 2016. doi: $10.1155 / 2016 / 4891803$

11. B. Rani and B.B.J. Basu, Green Inhibitors for Corrosion Protection of Metals and Alloys: An Overview, Int. J. Corros., 2012, 1-16. doi: 10.1155/2012/380217

12. J. Gray and B. Luan, Protective Coatings on Magnesium and its Alloys - A Critical Review, J. Alloys Compd., 2002, 336, no. 1-2, 88-113. doi: 10.1016/S0925$\underline{\text { 8388(01)01899-0 }}$

13. D.-H. Xia, J. Wang, Z. Wu, Z. Qin, L. Xu, W. Hu and J.-L. Luo, Sensing Corrosion Within an Artificial Defect in Organic Coating Using SECM, Sens. Actuators, B, 2019, 280, 235-242. doi: 10.1016/j.snb.2018.10.051

14. S.K. Dhoke, A. Khanna and T.J.M. Sinha, Effect of Nano-Zno Particles on The Corrosion Behavior of Alkyd-Based Waterborne Coatings, Prog. Org. Coat., 2009, 64, no. 4, 371-382. doi: 10.1016/j.porgcoat.2008.07.023

15. A. Jääskeläinen, K.-E. Peiponen, U. Tapper, E.I. Kauppinen and K. Lumme, Effective Refractive Index of Calcium Carbonate Pigment Slurries by A Surface-PlasmonResonance Sensor, Dyes Pigm., 2002, 52, no. 1, 15-21. doi: 10.1016/S01437208(01)00067-5

16. C.J. Patel and V. Mannari, Air-Drying Bio-Based Polyurethane Dispersion From Cardanol: Synthesis and Characterization of Coatings, Prog. Org. Coat., 2014, 77, no. 5, 997-1006. doi: 10.1016/j.porgcoat.2014.02.006 
17. A. Olad, M. Barati and S. Behboudi, Preparation of Pani/Epoxy/Zn Nanocomposite Using Zn Nanoparticles and Epoxy Resin as Additives and Investigation of its Corrosion Protection Behavior on Iron, Prog. Org. Coat., 2012, 74, no. 1, 221-227. doi: 10.1016/j.porgcoat.2011.12.012

18. C. Dange, T. Phan, V. André, J. Rieger, J. Persello and A. Foissy, Adsorption Mechanism and Dispersion Efficiency of Three Anionic Additives [Poly (Acrylic Acid), Poly (Styrene Sulfonate) and Hedp] on Zinc Oxide, J. Colloid Interface Sci., 2007, 315, no. 1, 107-115. doi: 10.1016/j.jcis.2007.03.068

19. W. Wu, M. Queiroz and N. Mohallem, The Effect of Precipitated Calcium Carbonate Nanoparticles In Coatings, J. Coat. Technol. Res., 2016, 13, no. 2, 277-286.

20. A. Abbasian, S. Ghaffarian, N. Mohammadi, M. Khosroshahi and M. Fathollahi, Study on Different Planforms of Paint's Solvents and The Effect of Surfactants (on them), Prog. Org. Coat., 2004, 49, no. 3, 229-235. doi: 10.1016/j.porgcoat.2003.09.020

21. R. Rosliza, W.W. Nik, S. Izman and Y. Prawoto, Anti-Corrosive Properties of Natural Honey on Al-Mg-Si Alloy in Seawater, Curr. Appl. Phys., 2010, 10, no. 3, 923-929. doi: 10.1016/j.cap.2009.11.074

22. D. Bouknana, B. Hammouti, S. Jodeh, A. Bouyanzer, A. Aouniti and I. Warad, Aqueous Extracts of Olive Roots, Stems, and Leaves as Eco-Friendly Corrosion Inhibitor For Steel in $1 \mathrm{M} \mathrm{HCl}$ Medium, Int. J. Ind. Chem., 2015, 6, no. 4, 233-245. doi: $10.1007 / \mathrm{s} 40090-015-0042-\mathrm{z}$

23. B. Ugi and F. Abeng, Corrosion Inhibition Effects and Adsorption Characteristics of Ethanol Extract of King Bitters Root (Andrographis paniculata) on Mild Steel in Hydrochloric and Tetraoxosulphate (VI) Acid Media, Fountain J. Nat. Appl. Sci., 2013, 2, no. 2, 10-21. doi: 10.13140/RG.2.2.31135.00166

24. K. Shirisha and M. Mastan, Andrographis paniculata and its Bioactive Phytochemical Constituents for Oxidative Damage: A Systemic Review, Pharmacophore, 2013, 4, no. 6, 212-229.

25. M. Maria, W. Ikhmal, M. Sabri and A. Adnan, Identification of Functional Group Present in Andrographis paniculata (Kalmegh) Leaves by FTIR analysis, Int. Fund. Sci. Symp., 2018, Terengganu, MY, 440, 1-6. doi: 10.1088/1757-899X/440/1/012035

26. P. Das and A.K. Srivastav, Phytochemical Extraction and Characterization of The Leaves of Andrographis Paniculata for its Anti-Bacterial, Anti-Oxidant, Anti-Pyretic and Anti-Diabetic Activity, Int. J. Innov. Res. Sci. Eng. Tech., 2014, 3, 15176-15184. doi: $10.15680 /$ IJIRSET.2014.0308016

27. S.W. Qader, M.A. Abdulla, L.S. Chua, N. Najim, M.M. Zain and S. Hamdan, Antioxidant, Total Phenolic Content and Cytotoxicity Evaluation of Selected Malaysian Plants, Molecules, 2011, 16, no. 4, 3433-3443. doi: 10.3390/molecules16043433

28. J.H. Chen and R.L. Jiang, Morphological and Histological Studies on Andrographis Paniculata (Burm. F.) Nees. and Comparison with Four Other Acanthaceae Herbs (Author's Transl.), Acta Pharm. Sin., 1980, 15, no. 12, 750-760. 
29. N.P. Trivedi and U. Rawal, Hepatoprotective and Antioxidant Property of Andrographis paniculata (Nees) In BHC Induced Liver Damage in Mice, Indian J. Exp. Biol., 2001, 39, 41-46.

30. A. Singh, V.K. Singh and M.A. Quraishi, Aqueous Extract of Kalmegh (Andrographis paniculata) Leaves As Green Inhibitor For Mild Steel in Hydrochloric Acid Solution, Int. J. Corros., 2010, 1-10. doi: 10.1155/2010/275983

31. N. Gajbhiye and S. Khristi, Distribution Pattern of Andrographolide and Total Lactones in Different Parts of Kalmegh Plant, Indian J. Hortic., 2010, 64, no. 4b, 591593.

32. M. Pérez, M. García, D. Ruiz, J.C. Autino, G. Romanelli and G. Blustein, Antifouling Activity of Green-Synthesized 7-hydroxy-4-methylcoumarin, Mar. Environ. Res., 2016, 113, 134-140. doi: 10.1016/j.marenvres.2015.11.010

33. A. Hamdy and N.S. El-Gendy, Thermodynamic, Adsorption and Electrochemical Studies for Corrosion Inhibition of Carbon Steel by Henna Extract in Acid Medium, Egypt. J. Pet., 2013, 22, no. 1, 17-25. doi: 10.1016/j.ejpe.2012.06.002

34. B. Sajeeb, U. Kumar, S. Halder and S.C. Bachar, Identification and Quantification of Andrographolide from Andrographis paniculata (Burm. f.) Wall. ex Nees by RPHPLC Method and Standardization of its Market Preparations, Dhaka Univ. J. Pharm. Sci., 2015, 14, no. 1, 71-78. doi: 10.3329/dujps.v14i1.23738

35. H.-h. Zhang, X. Pang, M. Zhou, C. Liu, L. Wei and K. Gao, The Behavior of PreCorrosion Effect on the Performance of Imidazoline-Based Inhibitor in 3 wt.\% $\mathrm{NaCl}$ Solution Saturated with $\mathrm{CO}_{2}$, Appl. Surf. Sci., 2015, 356, 63-72. doi: 10.1016/j.apsusc.2015.08.003

36. F. Berenji, H. Rakhshandeh, H. Ebrahimipour and F. Berenji, In Vitro Study of The Effects of Henna Extracts (Lawsonia Inermis) on Malassezia Species, Jundishapur J. Microbiol., 2010, 3, no. 3, 125-128.

37. O.Y. Vasylkiv, O.I. Kubrak, K.B. Storey and V.I. Lushchak, Cytotoxicity of Chromium Ions May be Connected with Induction of Oxidative Stress, Chemosphere, 2010, 80, no. 9, 1044-1049. doi: 10.1016/j.chemosphere.2010.05.023 